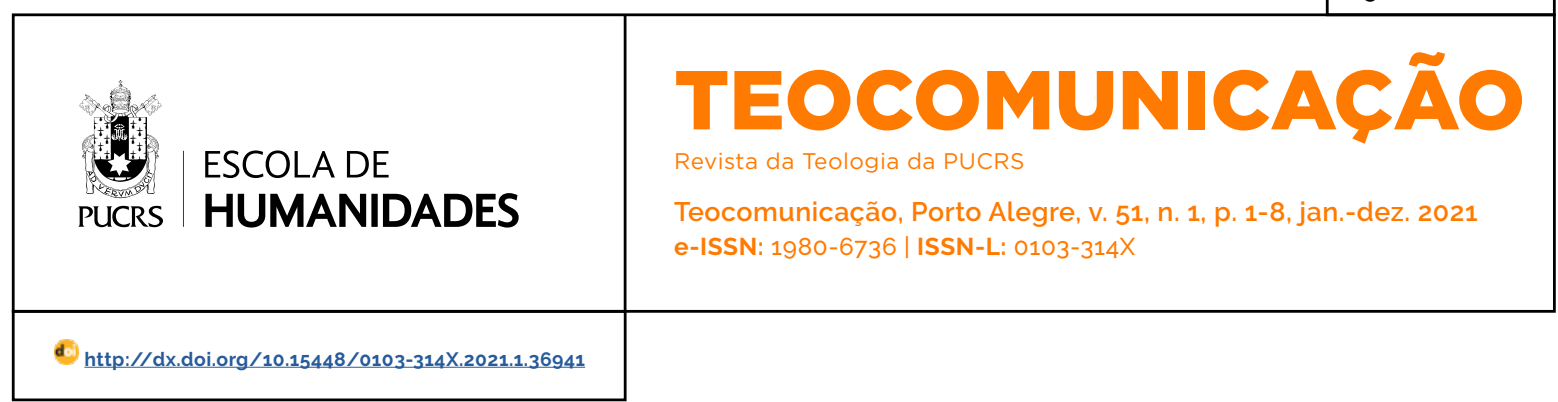

SEÇÃO: DOSSIÊ - EDUCAÇÃO PARA A PAZ

\title{
A identidade da educação católica no atual contexto
}

\author{
The identity of Catholic education in the current context
}

\section{Leomar Antônio \\ Brustolin ${ }^{1}$}

orcid.org/0000-0002-0066-4267

leomar.brustolin@pucrs.br

\section{Marcia Koffermann ${ }^{2}$}

orcid.org/0000-0003-1689-1509

marciak27@yahoo.com.br

Recebido em: 4 maio 2021

Aprovado em: 16 jul. 2021.

Publicado em: 23 ago. 2021.
Resumo: Este artigo trata da identidade da educação católica diante da pluralidade cultural atual. O artigo traz presente a concepção católica de mundo a partir dos escritos de diversos autores, especialmente Romano Guardini. O texto faz um paralelo entre a concepção católica de mundo e a atual realidade da educação católica, marcada pela competitividade no mercado educacional e pela diversidade de propostas que, por vezes, se distanciam de seu compromisso de catolicidade. O texto aborda a problemática da educação católica a partir de uma visão antropológica centrada na pessoa e apresenta alguns questionamentos básicos que podem servir para um aprofundamento da missão essencial da educação católica enquanto diferencial no contexto da educação. A reflexão aponta para a necessidade de que os ambientes católicos de educação sejam agentes transformadores da sociedade, a partir de uma concepção católica de mundo que dialoga com a realidade e que possibilita a inserção ativa do educador cristão frente às diferentes problemáticas que a sociedade atual apresenta. Palavras-chave: Educação Católica. Catolicismo. Cosmovisão. Romano Guardini. Formação Integral.

Abstract: This article deals with the identity of Catholic education in the face of current cultural plurality. The article presents the Catholic conception of the world from the writings of several authors, especially Romano Guardini. The text draws a parallel between the Catholic conception of the world and the current reality of Catholic education, marked by the competitiveness in the educational market and the diversity of proposals that are sometimes distant from its commitment to catholicity. The text addresses the issue of Catholic education from an anthropological perspective centered on the person and presents some basic questions that can serve to deepen the essential mission of Catholic education as a differential in the context of education. The reflection points to the need for Catholic educational environments to be transforming agents of society, based on a Catholic conception of the world that dialogues with reality and that enables the active insertion of the Christian educator in the face of the different problems that today's society presents. Keywords: Catholic Education. Catholicism. Worldview. Romano Guardini. Integral Formation.

\section{Introdução}

Vivemos hoje em um mundo plural. A facilidade proporcionada pelos meios de comunicação e pelo processo de globalização permite que diferentes ideias e concepções de mundo apareçam e se disseminem. Nesse horizonte de pluralidade é importante compreender o real papel da educação católica a partir da visão de mundo que essa contempla.

No atual contexto de individualidade e de pluralidade, repensar o significado e a missão da educação católica é uma necessidade urgente. Diante de um mundo que se transforma cabe se questionar: em que 
consiste a identidade confessional da educação católica? Como dialogar com as diferentes culturas e pontos de vista que emergem e definem questões antropológicas, éticas e morais? São questões abertas que precisam ser discutidas para a formação de uma identidade da educação católica, que seja coerente com a sua missão e aberta ao mundo que a rodeia. Partindo da perspectiva de Romano Guardini, é possível identificar algumas luzes para enfrentar esse questionamento. É necessário compreender os elementos que definem o significado lato da catolicidade. Isso implica conhecer o que o teólogo define como cosmovisão católica.

A cosmovisão está ligada à capacidade de compreender o mundo de forma totalitária, a partir da qual é possivel dar sentido ao ser e valorar cada coisa e ou situação. Uma concepção de mundo pode advir de uma matriz religiosa ou não. Conforme Guardini, as ciências também se esforçam para alcançar uma unidade última (GUARDINI, 1957, p. 25). Embora as ciências busquem também uma compreensão unitária do mundo, nelas predomina a fragmentação resultante de sua especialização, o que dificulta uma visão ampla e integral da realidade que vivemos. Afinal, a concepção de mundo "não consiste em uma integração plenária dos conteúdos objetivos, mas em uma ordem, direção e sentido das coisas, apreendido tudo isso desde o primeiro momento e em cada trama da realidade" (GUARDINI, 1957, p. 26).

Sobre essa forma totalitária de conceber o mundo, Romano Guardini aponta três aspectos importantes:

[...] primeiro, a totalidade do mundo como a soma e compêndio das coisas do mundo externo, às quais o homem também pertence em seu ser físico. Em segundo lugar, o homem, na medida em que constitui uma unidade fechada em si mesmo, e na medida em que, como eu individual e social, ele se opõe ao mundo. Enfim, fundamento absoluto e origem primeira do mundo e do homem: Deus (GUARDINI, 1957, p. 38).

Assim, a concepção ou visão de mundo está ligada a uma ampla conexão psiquica, a partir da qual é possivel encarar o próprio mundo, compreender-se enquanto ser humano e abrir-se diante do
Todo Absoluto. Para Guardini (1957, p. 43), a concepção de mundo é um todo complexo que pertence às atitudes cognitivas essenciais do homem.

\section{A concepção católica de mundo}

Dada esta primeira compreensão sobre a concepção católica do mundo, convém aprofundar o significado do adjetivo "católica". Ao apresentar-se como católica, essa concepção de mundo assume uma identidade própria, ligada expressamente à Igreja Católica Romana. Nesse sentido, sustenta Bernard Bartmann:

\begin{abstract}
A catolicidade tanto é propriedade interior da Igreja, como nota externa. Como diz o termo (universal) designa a extensão, no tempo e sobretudo no espaço, da Igreja entre todos os homens e em todos os paises. A catolicidade supõe a unidade; de fato, se as Igrejas esparsas por sobre a terra fossem independentes, não se poderia falar de catolicidade no espaço. Distingue-se, porém, a catolicidade atual da Igreja no mundo da vocação e da aptidão a esta extensão. Esta é naturalmente, mais antiga que a catolicidade de fato, de que é causa. Quando se diz que a igreja é católica, entende-se que ela recebeu de seu fundador a capacidade $e$ a missão de se estender no meio de todos os povos do mundo e que ela, desde os primeiros tempos da sua atividade, conscientemente procurou conforme a sua vocação, tornar-se a Igreja universal. Seu desenvolvimento não foi casual, mas querido e conforme a sua natureza (BARTMANN, 1964, p. 511).
\end{abstract}

Nessa mesma linha, para Congar, "a catolicidade é a propriedade da Igreja que faz com que a realidade da multiplicidade dela se harmonize com a da unidade" (SAMANES; TAMOYO-ACOSTA, 1999, p. 92).

O papa Bento XVI, aprofunda o sentido do termo ao afirmar que o adjetivo "católica",

[...] não exprime só uma dimensão horizontal, a
reunião de muitas pessoas na unidade; exprime
tambem uma dimensão vertical: só dirigindo
o olhar para Deus, só nos abrindo a Ele nos
podemos tornar verdadeiramente uma coisa
só. [...] Catolicidade significa universalidade,
multiplicidade que se torna unidade; unida-
de que permanece, contudo, multiplicidade.
[...] Catolicidade e unidade caminham juntas
(BENTO XVI, 2005).

A expressão católica, portanto, significa tanto a capacidade da Igreja em manter sua unidade quanto a de se estender em uma universalidade 
e multiplicidade de realidades no tempo e no espaço. Assim, pensar a educação católica implica saber que ela mantém uma unidade fundamental com a Igreja de Jesus Cristo, manifesta na mesma fé cristã, mas que também é chamada à universalidade, interagindo com as diferentes culturas e acolhendo a multiplicidade de situações que nela se inserem. Quando uma dessas dimensões é esquecida ou prejudicada em favor da outra, compromete-se a compreensão adequada do termo "católica" na educação.

O ser católico implica uma concepção católica de mundo, que segundo Romano Guardini tem a ver com a superação da fragmentação e com o olhar para a totalidade do mundo (GUARDINI, 1994, p. 18). Essa concepção de mundo que parte da totalidade e não se perde nas partes é uma visão que exige um distanciar-se do próprio mundo, o que exige uma superação:

A superação não poderia ser alcançada, digamos, por meio do meu distanciamento espacial ou temporal do mundo, porque no que diz respeito ao espaço e ao tempo, eu sempre permaneço no mundo. E nem mesmo por meio do meu distanciamento lógico do objeto que me leva a noções cada vez mais abstratas-universais; mesmo assim eu sempre vou permanecer no mundo. Uma posição "externa" do mundo só poderia consistir no fato de que algo absolutamente sobrenatural surgiu dentro do reino de determinadas realidades. Isso seria heterogêneo, de um gênero diferente do que no mundo, e sua importância seria baseada na criação e libertação (GUARDINI, 1994, p. 30).

Essa posição externa ao mundo não é possivel ao ser humano comum, somente com a Encarnação do Verbo é possível falar de um olhar externo, mas sem abandonar esse mundo. Um olhar do Totalmente Outro, mas que fala e se expressa em ações concretas neste mundo, como realizou Jesus Cristo:

Nele, o Deus livre do mundo fala sobre o mundo. No encontro com Ele, a verdadeira essência do mundo é revelada; diante dEle, o bem e o mal se manifestam; diante dEle, os homens trazem as consequências do que há em seu intimo "os corações "do alto" (GUARDINI, 1994, p. 31).

Somente em Cristo é que podemos ter esta visão de totalidade do mundo, Ele que não é do mundo, não deixa de estar no mundo. Pelo mistério da Encarnação o ser humano é capaz de perceber e de compreender, ao menos minimamente, o olhar de Deus sobre o mundo:

Em Cristo, vemos como Ele vê o mundo em sua totalidade e o vê justo. Como Ele Fala a Palavra com confiança, respeito e independência juntos. Como ele resolve resolutamente as necessidades do momento - que, no entanto, está no mesmo tempo ou "plenitude do tempo" - com a consciência de uma missão que é direcionada precisamente a esse momento. Cristo tem o olhar verdadeiramente pleno do Weltanschauung. $\mathrm{O}$ olhar do Weltanschauung e o olhar de Cristo Ele permanece (GUARDINI, 1994, p. 32).

Nesse sentido, a visão católica de mundo é a visão do próprio Cristo. Um olhar que dificilmente somos capazes de compreender e absorver, porque Cristo olha o ser humano em sua inteireza. Trata-se de um olhar que exige a fé e atinge a concepção de ser humano, mundo e ética.

Aqui se encontra um primeiro e grande desafio da educação católica atual: educar para olhar o mundo a partir do olhar de Cristo. Não um Cristo idealizado, mas o Cristo do Evangelho que vence assumindo a cruz, que tem o olhar voltado para o outro, que é capaz de olhar a essência, um olhar revelador e que ilustra o amor misericordioso do Pai que enviou o seu Filho para salvar o mundo e não para condená-lo. A concepção católica do mundo envolve, portanto, um olhar global que permite agir localmente sem perder a essência daquilo que é o todo: a verdade do Evangelho.

\section{A educação a partir da concepção católica de mundo}

Toda educação, por natureza tem, ou deveria ter, o objetivo de garantir excelência acadêmica capaz de promover a transformação da sociedade em um lugar mais humano e solidário - esse é um primeiro dado inegociável. À educação católica acrescesse-se a missão de ser capaz de oferecer também uma formação humana e cristã que permita uma verdadeira síntese entre fé e vida. Já em 1977, a Sagrada Congregação para a Educação Católica assim se referia ao propósito do ensino: 
Fundado na assimilação dos valores objetivos, o ensino, na sua dimensão apostólica, não se limita à sintese entre fé e cultura, mas tende a realizar no aluno uma sintese pessoal entre fé e vida. A escola Católica assume como sua função especifica - e hoje, perante as faltas da familia e da sociedade neste setor, com maior razão - a formação da personalidade cristã do aluno; em ordem à atuação da sintese entre fé e vida na pessoa do aluno, é consciente de que o homem deve ser formado num processo de conversão contínua, para poder ser aquilo que Deus quer que ele seja. Ensina os jovens a dialogar com Deus nas várias situações da sua vida pessoal. Além disso, estimula-os a superar o individualismo e a descobrir, à luz da fé, que são chamados a viver de maneira responsável uma vocação específica em solidariedade com os outros homens (A ESCOLA CATÓLICA, n. 44 e 45).

O ensino católico não supõe simplesmente ser uma instância de educação, mas é uma instituição a serviço da sociedade, em que as problemáticas do cotidiano e as grandes questões da humanidade são tratadas à luz do Evangelho, buscando uma transformação social, em que se tenha prioridade a dignidade humana, o bem comum e o cuidado com a vida. Para tanto, o diálogo aberto e respeitoso com outras instituições civis e eclesiais é fundamental, colocando em prática a sua natureza original voltada para a missionariedade.

É assim necessário que também no nosso tempo a escola católica saiba afirmar-se de maneira eficaz, persuasiva e atual. Não se trata de pura adaptação, mas de impulso missionário: é o dever fundamental da evangelização, de ir até onde está o homem para que acolha o dom da salvação (A ESCOLA CATÓLICA, n. 3).

A educação católica é, portanto, um espaço importante que permite a formação de uma ampla conexão psíquica, conforme aponta Romano Guardini, que tenha como fundamento a totalidade do ser, em uma concepção de mundo que parte do olhar de Cristo. Essa é a mais profunda liberdade que a pessoa pode adquirir. Conforme a Exortação apostólica Evangelii Nuntiandi, essa capacidade de olhar implica em uma mudança interior.

Essa mudança interior é justamente a mudança de ótica necessária, que faz com que cada cristão, progressivamente adquira, por meio de diferentes experiências, o olhar de Cristo sobre o ser humano. Essa antropologia que valoriza tanto os direitos pessoais quanto estimula a participação comunitária e social é expressão da dignidade humana que Cristo revela em todo seu Evangelho. Para a Igreja trata-se de atingir e até de modificar, pela força do Evangelho, "os critérios de julgar, os valores que contam, os centros de interesse, as linhas de pensamento, as fontes inspiradoras e os modelos de vida da humanidade, que se apresentam em contraste com a Palavra de Deus e com o desígnio da salvação" (PAULO VI 1986, n. 19).

A educação católica tem, portanto, caracteristicas próprias que the conferem a possibilidade de participar e ser parte da missão evangelizadora da Igreja de Jesus Cristo. São raízes profundas que a distingue das demais propostas educativas e, essa diferença, precisa ser vista e perceptivel pela sociedade.

\section{A educação como serviço eclesial}

A Igreja possui a responsabilidade de evangelizar, proporcionando às novas gerações o contato e a vivência do Evangelho de Jesus Cristo, para tanto, utiliza-se de inúmeros meios, entre os quais, a educação. Essa é uma instância eclesial de suma importância e, portanto, precisa ser cuidada e pensada de modo a ser um espaço onde se vive e se transmite a visão católica de mundo. É próprio das instituições educativas católicas criar um ambiente de comunidade, animado pelo espírito evangélico de liberdade e de caridade, ajudando os estudantes para que, ao mesmo tempo que desenvolvem a sua personalidade, cresçam segundo a nova criatura que são a partir do seu Batismo, e ordenar finalmente toda a cultura humana à mensagem da salvação, de tal modo que seja iluminado pela fé o conhecimento que os estudantes adquirem gradualmente a respeito do mundo, da vida e do ser humano (GRAVISSIMUM EDUCATIONIS, n. 8).

Esse ambiente educativo pastoral em que vai se moldando a visão cristã do mundo, precisa ser pensado de forma intencional e colaborativa. Os educadores, especialmente, precisam estar imbuídos de uma visão cristã da vida para que possam trazer presente a realidade do mundo, em uma 
perspectiva do Evangelho de Cristo. Isto é bastante complexo no atual contexto, em que muitos educadores são altamente capacitados em suas áreas de atuação, mas, muitas vezes, não passaram por um adequado processo de educação na fé ou, ainda, professam outra fé, que não a católica.

Quando Romano Guardini fala sobre o ser católico, não ignora de forma alguma a verdade e a força que possam existir nas confissões não católicas, nem ignora quão limitada e deficiente é a representação do catolicismo, e quão longe ela permanece de seu ser essencial (GUARDINI, 1957. p. 57). Entretanto, mesmo com as limitações que cada pessoa apresenta, cada uma contribui para o processo de evangelização, sabendo que esse é um processo de toda a comunidade cristã. Isso implica em formar melhor os educadores católicos para conhecer e viver a comunhão eclesial, pois,

[...] se cada um evangeliza em nome da Igreja, o que ela mesma faz em virtude de um mandato do Senhor, nenhum evangelizador é o senhor absoluto da sua ação evangelizadora, dotado de um poder discricionário para realizar segundo critérios e perspectivas individualistas tal obra, mas em comunhão com a Igreja e com os seus Pastores (PAULO VI, 1986, n. 60).

O educador não é mero transmissor de saberes, mas mestre capaz de provocar e instigar os educandos a saberem e a serem mais humanos. É o testemunho autêntico que fala com a vida em busca de um mundo mais humano, digno e amoroso. É, portanto, um discipulo missionário que tem em suas mãos o delicado trabalho de conduzir os educandos em um caminho de humanização, pois a educação católica deve ser "centrada na pessoa humana que é capaz de viver na comunidade oferecendo a esta o bem que a Igreja possui" (CONSELHO EPISCOPAL LATINO-AMERICANO, 2007, n. 334).

Na educação em perspectiva católica, não se trabalha com um aglomerado de indivíduos, mas com "pessoas". Ser pessoa, é mais do que ser um indivíduo qualquer, significa tratar cada um como "Filho de Deus", criado a sua imagem e semelhança. Pessoa, enquanto ser de relação com o outro, consigo mesma e com o Divino é alguém com uma dignidade sagrada. O conceito compreende que o Eu existe a partir da experiência do Tu. Os relacionamentos são essenciais na constituição da pessoa humana.

Nessa perspectiva da relação, a comunidade torna-se um lugar imprescindivel, nela as pessoas vivem experiências únicas e buscam realizar a vontade de Deus, abrindo-se para a acolhida de si, do outro e do Transcendente. Mesmo que cada pessoa tenha as suas singularidades típicas, há uma unidade que perpassa a todos e constitui o ser católico, essa unidade "não está mais no indivíduo, mas na comunidade" (GUARDINI, 1957, p. 66). Na visão de Romano Guardini, "a atitude católica concorre, colocando o indivíduo na comunidade da lgreja, de modo que nesta totalidade encontre a fonte do seu pensamento, da sua vida e sua ação" (GUARDINI, 1957, p. 68). Assim, a educação católica precisa estar aberta e formada para a constituição de comunidades radicadas e alicerçadas a partir do olhar de Cristo. Se a instituição educativa não está em comunhão efetiva com a comunidade eclesial da qual faz parte, perde sua catolicidade. Cada vez mais urge uma interação das instituições de ensino católicas com as paróquias e as dioceses, para que se sintam pertencentes e em comunhão. A experiência cristã vivida na Ordem Congregação ou Movimento, por mais rica que seja, seria incompleta se não concebesse esse vínculo com a Igreja que se expressa concretamente em cada localidade.

\section{A profecia católica em tempos de educação como produto}

Não é novidade o fato de que, a educação vem se tornando um forte mercado em que se oferece um serviço em vista da obtenção do lucro. É um espaço de grande concorrência, disputado por grupos educacionais cada vez maiores e mais influentes, muitas vezes, de origem internacional. Questões como qualidade de ensino, preço, visibilidade da marca, valores, inovação e tradição são diferenciais que podem trazer prestígio ou descartar a instituição por não atingir o público necessário para sua subsistência.

A educação católica caracterizada por valores sólidos, tradição e reconhecimento na sociedade, 
passa a ter que enfrentar uma situação de liquidez de valores, pensamento, comportamentos e estilos de vida que se afastam do projeto de vida pautado pelo Evangelho. Algumas instituições acabam tendo que se sujeitar ao contexto, moldando-se aos interesses individuais e grupais e deixando de lado valores essenciais, outras insistem em manter um modelo tradicional, sólido e inflexivel, mas sem muita adesão diante das propostas comerciais, e outras, a maioria, encontram-se como que sem saber que rumo tomar diante da agressiva e, muitas vezes, desleal concorrência que enfrentam.

Se a educação católica perde sua identidade e características fundamentais, a sua relevância perde o sentido e passa a ser apenas mais uma proposta entre tantas outras, não cumprindo sua missão de formar uma concepção católica de mundo a partir do seu processo de evangelização. Esquece-se o que disse Romano Guardini, de que a concepção católica do mundo e que é compartilhada pela Igreja, se fundamenta nas "profundezas do Cristo vivo e na plenitude de uma totalidade que paira sobre todos os tipos" (GUARDINI, 1957, p. 70). Seguindo essa lógica, as instituições educativas, enquanto espaços católicos de educação à fé, deveriam ter como primeiro objetivo, fazer com que as novas gerações recebam essa visão e participem do olhar de Cristo e esse objetivo não pode ser negociado. Não se pode fazer nenhuma concessão ao mercado, à concorrência e ao marketing esquecendo ou camuflando a força profética do Evangelho. Afinal, o cristão, como Cristo, está neste mundo sem se confundir com este mundo. Uma educação pautada por valores típicos de uma sociedade desigual e injusta, pode atrair muitos estudantes e ter excelentes resultados financeiros, mas dificilmente promoveria os valores do humanismo integral e solidário proposto pela Igreja.

Para a concretização de uma educação católica profética e de acordo com os tempos, em sua mensagem sobre o Pacto Educativo Global, - Papa Francisco aponta três posicionamentos corajosos que a escola precisa ter:
Primeiro, ter a coragem de colocar no centro a pessoa. [...]. Num percurso de ecologia integral, coloca-se no centro o valor próprio de cada criatura, em relação com as pessoas e com a realidade que a rodeia, e propõe-se um estilo de vida que rejeite a cultura do descarte.

Outro passo é a coragem de investir as melhores energias com criatividade e responsabilidade. [...]. Assim, teremos pessoas abertas, responsáveis, disponiveis a encontrar o tempo para a escuta, o diálogo e a reflexão, e capazes de construir um tecido de relações com as familias, entre as gerações e com as várias expressões da sociedade civil de modo a constituir um novo humanismo.

Coragem de formar pessoas disponiveis para se colocarem a serviço da comunidade. 0 serviço é um pilar da cultura do encontro: "significa inclinar-se sobre quem é necessitado e estender-lhe a mão, sem cálculos nem receio, com ternura e compreensão, como Jesus Se inclinou para lavar os pés dos Apóstolos. Servir significa trabalhar ao lado dos mais necessitados, estabelecer com eles, antes de tudo, relações humanas, de proximidade, vínculos de solidariedade" (MENSAGEM DO PAPA FRANCISCO PARA O LANÇAMENTO DO PACTO EDUCATIVO, 2019).

A proposta do Papa Francisco para o Pacto Educativo Global está plenamente de acordo com a concepção católica de mundo que defende Romano Guardini. Primeiramente, ao colocar a pessoa no centro, reflete a atitude de Cristo que valoriza cada um em sua unicidade, enquanto imagem e semelhança de Deus, formando o conceito de irmandade e fraternidade que perpassa e caracteriza o Cristianismo. Em segundo lugar, a abertura para a escuta, o diálogo e a reflexão são características, o catolicismo implica pluralidade e diversidade na unidade. Relembrando as palavras de Guardini:

A imagem do mundo de Santo Agostinho é
profundamente diferente da de Santo Inácio
de Loyola. Tomás de Aquino vê o mundo de
maneira diferente do cardeal Newman. Todos
são, inquestionavelmente, católicos, mas inques-
tionavelmente eles também diferem na forma
como abordam o mundo (GUARDINI, 1957, p. 59).

Esta é uma das riquezas da concepção católica do mundo, que permite a partir de uma totalidade, prever e aceitar as diversidades sem cair no mero relativismo, porque tem um centro, um ponto fixo, que é o olhar de Jesus Cristo sobre a realidade. E, por fim, o colocar-se a serviço da comunidade. 
Para Guardini, "a Igreja é o depositário histórico da visão integral de Cristo do mundo"(GUARDINI, 1957. p. 67), é na vida comunitária, no serviço aos mais pobres e necessitados que cada fiel pode involucrar-se da visão integral de Cristo sobre o mundo.

A formação integral da pessoa, aliada à construção de uma sociedade mais justa e fraterna, são características essenciais do pensamento cristão e devem fazer parte do processo de síntese entre fé e vida. Assim, a comunidade educa e educa-se constantemente buscando sempre respostas mais adequadas aos grandes problemas da humanidade e aos anseios dos jovens que frequentam esse ambiente em seu cotidiano.

O Projeto Educativo Católico deveria ser uma proposta de apresentação do modelo evangélico de vida que se configura em torno da pessoa de Jesus Cristo. Para isso não bastam aulas de Ensino Religioso, ou algumas práticas pastorais pontuais no decorrer do ano, é necessário um movimento de toda a comunidade educativa voltado para o testemunho da vida cristã e a abertura aos valores evangélicos em todos os aspectos do conhecimento. Em outras palavras, necessita-se de um projeto educativo que se ocupe da sintese entre fé e vida, entre fé e razão, tendo como elemento sólido, e centro da proposta, Jesus Cristo, Verdadeiro Deus e Verdadeiro Homem. Com Cristo, toda comunidade escolar há de ter "mais vida e vida em abundância" (Jo 10,10)

\section{Considerações finais}

A questão da identidade na educação católica atual é um elemento essencial não apenas para a sua relevância em um mundo plural, mas para a vida da Igreja, que precisa estar presente em diferentes instâncias para concretizar o mandato missionário que recebeu de Cristo. A compreensão do significado da catolicidade amplia o olhar passando de um mero pertencimento à Igreja para um espaço no qual se irradia a fé a partir do olhar de Cristo sobre o mundo.

A educação católica tem o dever de transmitir e construir com os membros de sua comunidade o olhar evangélico sobre o mundo, propondo-se para tanto uma postura crítica diante das cos- movisões míopes que não enxergam o futuro e a transcendência, quanto uma postura profética que defenda o humanismo integral e solidário, especialmente, voltando-se para os pobres não com gestos de filantropia, mas de autêntica caridade e justiça que a misericórdia de Cristo impõe aos seus seguidores. Sem essa visão profética, pode-se manter uma proposta educativa no mercado, mas certamente ela seria estranha a Cristo e ao Evangelho.

\section{Referências}

BARTMANN, Bernardo. Teologia Dogmática. Revelação e fé - Deus - A criação. São Paulo: Paulinas, 1964. v. 2.

BENTO XVI. Homilia na solenidade dos Santos Apóstolos Pedro e Paulo. Roma, 29 jun. 2005. Disponivel em: http://w2.vatican.va/content/benedict-xvi/pt/homiLies/2005/documents/hf_ben-xvi_hom_20050629_sts-peter-paul.html Acesso em: 11 abr. 2019.

CONCÍLIO VATICANO II. Gravissimum Educationis in Compêndio do Vaticano II: constituições, decretos, declarações. Petrópolis: Vozes, 2000.

CONGREGAÇÃO DA EDUCAÇÃO CATÓLICA. A escola católica no limiar do terceiro milênio. Roma, 28 dez. 1997. Disponivel em: http://www.vatican.va/roman_curia/ congregations/ccatheduc/documents/rc_con_ccatheduc doc 27041998 school2000 po.html. Acesso em: 11 abr. 2019.

CONGREGAÇÃO PARA A EDUCAÇÃO CATÓLICA. Educar Hoje e Amanhã: uma paixão que se renova. Roma, 7 abril, 2014. Disponivel em: http://www.vatican.va/ roman_curia/congregations/ccatheduc/documents/ rc_con_ccatheduc_doc_20140407_educare-oggi-e-domani_po.html. Acesso em: 11 abr. 2019

CONSELHO EPISCOPAL LATINO-AMERICANO. Documento de Aparecida: texto conclusivo da V Conferência Geral do Episcopado LatinoAmericano e do Caribe. São Paulo: Paulus: Paulinas; CNBB: Brasília, 2007.

FRANCISCO. Exortação Apostólica Evangelii Gaudium. In: Vaticano. 2013. Disponivel em: http://w2.vatican.va/ content/francesco/it/apost_exhortations/documents/ papa-francesco_esortazione-ap_20131124_evangelii-gaudium.html. Acesso em: 11 abr. 2019.

FRANCISCO. Mensagem do Papa Francisco para o lançamento do Pacto Educativo. In: Vaticano: 2019. Disponivel em: http://www.vatican.va/content/francesco/pt/ messages/pont-messages/2019/documents/papa-francesco_20190912_messaggio-patto-educativo.html

GUARDINI. Romano. La Visione Cattolica del Mondo. Brascia: Mocelliana, 1994

GUARDINI, R. La esencia de la concepción católica del mundo. México: Universidad Nacional Autónoma de México, 1957 
PAULO VI. Exortação Apostólica Evangelii Nuntiandi. São Paulo: Paulinas, 1986.

REDE SALESIANA BRASIL DE ESCOLAS. Escola Salesiana América: IV Encontro Continental. Brasília: CISBRASIL: CIB, 2018.

SAGRADA CONGREGAÇÃO PARAA EDUCAÇÃO CATÓLICA. A Escola Católica. In: Vaticano. Roma, 19 mar. 1977. Disponivel em: http://www.vatican.va/roman_curia/ congregations/ccatheduc/documents/rc_con_ccatheduc_doc_19770319_catholic-school_po.html. Acesso em: 11 abr. 2019.

SAMANES, Cassiano F.; TAMOYO-ACOSTA Juan J. Dicionário de conceitos fundamentais do cristianismo. São Paulo: Paulus, 1999.

\section{Leomar Antônio Brustolin}

Doutor em Teologia pela Universidade São Tomás de Aquino (PUST), em Roma, Itália; professor no PPG em Teologia da Pontifícia Universidade Católica do Rio Grande do Sul (PUCRS), em Porto Alegre, RS, Brasil.

\section{Marcia Koffermann}

Doutoranda em Comunicação Social pela Universidade de Huelva (UHU), Espanha. Mestre em Teologia Sistemática pela Pontifícia Universidade Católica do Rio Grande do Sul (PUCRS), Porto Alegre, RS, Brasil. Diretora executiva da Rede Salesiana Brasil de Comunicação.

\section{Endereço para correspondência}

Leomar Antônio Brustolin

Av. Ipiranga, 6681, Prédio 8, Sala 405

Partenon, 97010082

Porto Alegre, RS, Brasil

Marcia Koffermann

Travessa Padre Broggi, 45

Bairro Fortaleza, 96640-000

Rio Pardo, RS, Brasil

Os textos deste artigo foram revisados pela Poá Comunicação e submetidos para validação do autor antes da publicação. 